\title{
Theme of Loneliness in Anuradha Roy's The Folded Earth: A Psychological Study
}

\author{
Shereen Zaidi $^{1} \&$ Nitin Bhatnagar ${ }^{2}$
}

${ }^{1}$ Research Scholar, Department of English, GLA University, Mathura (India)

${ }^{2}$ Professor, Department of English, GLA University, Mathura (India)

\begin{abstract}
Loneliness is a feeling in which makes a person feel lack of togetherness with others. In this state, whether a person is alone or in company with others, feels emptiness. If this condition persists for a long time, its consequences can be disastrous, mentally as well as physically. Loneliness is a serious problem of the 21 st century and is the cause of suffering for many people today. Many psychologists and scholars have discussed its causes and ways to come out of its cluthes. Anuradha Roy, in her novel "The Folded Earth" has raised the social as well as psychological concerns related to loneliness. The present paper is an attempt to study not only its implications in the novel, but also to explore its causes and ways to deal with in real life. This research can be helpful especially for loners to understand their loneliness and recognize how it can be overcome.
\end{abstract}

Article Received: 18 October 2020, Revised: 3 November 2020, Accepted: 24 December 2020

\section{Introduction}

Loneliness, in a general sense, is a personal state of mind or a feeling which devours human beings inside and hollows painfully. Therefore, many theorists and scholars suggest against staying lonely for it can result in depression, stress, negativity due to less communication with others. Chang et. al. remarks:

....We found that loneliness was a positive predictor of depressive symptoms and suicide ideation in college students. Indeed, loneliness was found to account for a large amount of variance in both of the indices of suicidal risk. In keeping with various theories that have often posited that interpersonal disconnectedness from others is a critical component of adult (2017).

This does not apply only to the adults. Loneliness has also very bad consequences for older people as well. Courtin et. al. studied- "Out of the 32 papers on depression, 25 looked at its association with loneliness...loneliness is an independent risk factor for depression...." (2017). It can make people ill due to sense of incompletion and grief. Loneliness does not have to do anything with isolation or crowd as Louise Hawkley describes:

....The experience of loneliness is highly subjective; an individual can be alone without feeling lonely and can feel lonely even when with other people....Prolonged loneliness is associated with depression, poor social support, neuroticism, and introversion. Studies have shown that loneliness puts people at risk for physical disease and that it may contribute to a shortened life span (2007).

The point that an individual can be alone without feeling lonely, is a positive point in a way because in this situation a person is productive and a witness of his inner self. In this line Hawkley is using the word'alone' which means isolation or solitude. This point is to be noted. It means that there is a difference between aloneness and loneliness. Aloneness stands for a state where a person is in isolation or in solitude but not necessarily lonely, because loneliness is a psychological state, mixed with emotions of sadness, distress, neuroticism and melancholy. Hawkley's view that an individual feels lonely even when with other people is a negative state. If a person himself is not able to connect with others, even when he wants to, then it is a bad situation. On the other hand, Hawkley is calling loneliness, a distressing experience with a sense of deficiency of social relationships in quantity as well as in quality. He means by 'relationships less in quantity and quality'- a consistent feeling of deficiency of relationships and alignment. No matter how many relationships a lonely person forms, he still feels lonely.

Psychologists, according to their experience, have thrown light on loneliness. Friedman conveys the 
view of Freud by commenting- "The all-important loneliness of mankind was inborn; Freud said the conflict of instinctual drives means that human beings are born into a sense of loss and abandonment..." (2013). Pangs of loneliness, bounce from inside. Carl Gustav Jung takes it to need of communication: "Loneliness does not come from having no people around, but from being unable to communicate the things that seem important to one, or from holding certain views which others find inadmissible" (1989, p. 356). Erich Fromm opines: "It was culturally created...that the race is born with a sense of connectedness that is destroyed by the social climate" (2013). Bill Callanan illustrates- "Loneliness is most frequently associated with a sense of the loss of contact with other people, or with personal feelings of isolation, and is often counted among the factors which bring about depression" (1997). Thomas Oppong relates loneliness to connectedness like Fromm. He calls it a survival mechanism which drives us to connect with others. "But realistically, those deep connections we crave are not easy to find. When people fall short of the connections they desire and their only choice is superficial socializing or nothing, they can get lonely" (2019).

Loneliness and isolation are two different entities of human emotions. Tanskanen et al. clear the distinction between the two- "Social isolation is concerned more with environmental impoverishment or restriction than with the individual's ability to create and maintain social relationships. Loneliness is a subjective feeling of being without the type of relationships one desires" (2016). Isolation is a choice but loneliness is a compulsive suffering. The state of being with no-one is called isolation but it does not necessarily mean that in isolation, the person feels lonely too. A person can feel happy or sad in isolation. It is also referred to as solitude or aloneness. However, loneliness is a sad feeling in which person feels lack of togetherness, is distressed, alienated and hollowed whether in public or in isolation.

Anuradha Roy, the Author

Anuradha Roy is an Indian novelist, born in 1967 in Calcutta. She grew up mainly in Hyderabad and studied English literature. Anuradha Roy has four novels to her credit 'An Atlas of Impossible Longing' (2008), 'The Folded Earth' (2011), 'Sleeping on Jupiter' (2015), and 'All the Lives We Never Lived'
(2018). She also contributes articles in newspapers, writes non-fiction and inspirational stories for children. Roy is the only Indian among the thirteen novelists long-listed for the Man Booker Prize (2015). She has won 'DSC Prize' (2016) for 'Sleeping on Jupiter', Economist Crossword Book Award (2011) for 'The Folded Earth', Tata Book of the Year Award (2019) for Fiction for 'All the Lives We Never Lived'.

The themes of Roy's are related to human emotions of respect, love, attention, isolation, Loneliness, freedom, comfort, abandonment, individuality, desire for money, search of identity, longing, family relationships, incompatibility with parents, revenge etc. Social issues like hypocrisy, molestation, cruelty, child abuse, war, violence, futility of war, inequality, racism, male dominance etc. can also be seen in her writings. She is strongly opposed to inequality and racism about which she talked in an interview, also form part of her novels- "Inequality in India has never been more catastrophic" ("Inequality...., 2018) Along with this, Anuradha Roy is also interested in seeing the contexts of present and past, at one place. "And as I found out more about these people who lived during a fraught historical period, it felt as if the past and present were swimming in and out of each other" (We are...., 2020), she comments. Out of all the contributions of Roy, the novel The Folded Earth is being taken for present research.

\section{The Novel: The Folded Earth}

The Folded Earth is a deeply moving tale of human emotions, particularly dealing with loneliness. It is a story of a young woman Maya who is the protagonist narrator, disinherited by her father because of her wish to live life on her own conditions. She marries a Christian man named Michael. On this her father disowns and disinherits her. She is disheartened, and still she prepares herself mentally for living life with her husband confidently. Unfortunately, her husband dies on a mountaineering expedition. She is shattered as she knew her husband, the only true lover of her. Instead of going to her parents she seeks refuge in Ranikhet, a Himalayan hill town. There Maya teaches in a Christian school and resides in the house of Diwan Sahib. A love affair blossoms between Maya and Diwan Sahib's nephew, Veer, a mountaineering guide. However, later she is also betrayed by Veer. It is a story of a struggling woman who wants freedom, 
isolation and her own identity. She is persecuted as she was disowned by her father and in a way betrayed by the Mountaineering guide (Veer) incidentally.

On superficial level, the novel appears to deal with the problems related to society, dirty politics, male dominance, betrayal, racism, exploitation, helpless women etc. But if one tries to go behind the curtain, one will find some deep undercurrents of psychological issues like- loneliness, isolation reclusiveness and unknown desire of dissociation.

\section{Loneliness: The Main Problem in The Folded Earth}

Loneliness is a dominant issue in the novel. Loneliness is rife in most of the characters of the novel, in addition to Maya, the protagonist. It affects her mother, her father, an aging aristocrat Diwan Sahib, the mountaineering guide Veer, the student of Maya Charu, Charu's lover Kundan, Charu's mother Ama and Charu's half-witted uncle Puran. When viewed from a distance it will appear as the characters are responsible for one-another's loneliness. But, if seen objectively, one finds that a man's state depends entirely on man's own volition and deep rooted psychological conditions and personality developments. Erik Erikson maintains in his famous personality development theories:

Personality develops in a predetermined order through eight stages of psychosocial development, from infancy to adulthood. During each stage, the person experiences a psychosocial crisis which could have a positive or negative outcome for personality development....Failure to successfully complete a stage can result in a reduced ability to complete further stages and therefore a more unhealthy personality and sense of self (quoted in Mcleod, 2018).

He tells that behind the behavior of a human being not only he himself, but also his surroundings, emotions and psychological trends play vital role behind one's behavior. The Folded Earth also makes a bridge between humans and their environment. Komal Rakwal says- "The Folded Earth opens the various possibilities between individual and his environment" (2020). Erikson, illustrating from one of his experiments, explains the role of parent's and their ancestor's conflicts in shaping a personality (1963). Then Erikson explores life history or biography behind the pathological aspects of patients to cure. (quoted in Kemph, 1969, p. 154). Alfred Adler, another acclaimed psychologist, also casts light on this: "The unreasonable demands made on a child by a foolish environment are comparable to actual difficulties in the environment" (1927, p.31). Guy Winch says about loneliness:

Unfortunately, emerging from loneliness is far more challenging than we realize, as the psychological wounds it inflicts create a trap from which it is difficult to break free. Loneliness distorts our perceptions, making us believe the people around us care much less than they actually do, and it makes us view our existing relationships more negatively, such that we see them as less meaningful and important than we would if we were not lonely (Oct, 2015).

For example, Maya feels low due to less care by Veer. Some disoriented thoughts hammer her mind- "how long was he here? Did he come to my cottage? Did he not try to find me? Did he ask Ama about me? How could he have left without a word to me (Roy, p. 240)?" According to Winch, these kinds of distorted perceptions make people lonelier. Later, it will be clear after studying the psychological condition of Veer that indirectly he also goes through with the same problem. In his childhood, he too craved for care and affection. $\mathrm{He}$ also felt a lack of affinity. The same situation is with Maya's mother also when Maya left her maternal home forever. Mother felt all alone without her only daughter. Ama too feels lonely due to her elder son's and daughter in law's untimely death. She feels lack of care because her younger son, Puran is half-witted man and indirectly he continues to cause her trouble. Charu also feels lonely at a stage when her lover, Kundan's attitude changes. She too feels lack of love and care. In the novel, mostly everyone is suffering from loneliness more or less; knowingly or unknowingly.

\section{Loneliness in the Characters of The Folded Earth}

The loneliness of people is mostly due to physical separation. Although this distance can be temporary too but still, a person who is prone to feel lonely can have a deep pain and fear of separation. Perlman and Peplau write- "Loneliness is precipitated by changing in a person's social relationships that lead to a sub-optimal level of achieved social interactions" (1981). However Maya's loneliness was a result of permanent physical separation from her loved ones. Maya, as a kid, was a pampered child, especially of her wealthy father. Maya was a talented child so his 
expectations from her, were high. He dreamt of making her a successful businesswoman. He was very happy about the thought of handing his legacy over to his daughter with pride, unaffected with the thought of not having a son. But time is not always the same. When Maya grows up, everything changes. She marries a Christian man, Michael and the father takes it as shattering of his dreams. Under the pressure of society he disowns and disinherits her mercilessly. Michael's parents do not accept Maya. Therefore she goes afar with Michael to start a new life with him. After Michael's death she goes to Ranikhet, a Himalayan hill town. She stays there and starts finding happiness in the people around her. She says, "But I was at home. I had got used to thinking of Charu, her grandmother, her half-witted uncle, sanki Puran, and my landlord Diwan Sahib as my family now" (Roy, 2011, p. 21). Meanwhile she meets Veer and falls in love with him but after all, he too does not become hers.

Everyone left Maya alone hence she suffers from acute loneliness throughout the novel. Many of Maya's dialogues in the novel prove that she feels lonely. She says- "I was alone. I had no contact with friends: I had lost them over the years of being wrapped up in Michael. I had in fact no family although my parents did live in the same city" (p. 11). It is seen here as if loneliness is devouring Maya. Further in the novel again she says- "I felt utterly, absolutely alone. Wrapping my arms around my knees, I held myself as body shook with sobs" (p. 246). When Maya comes to know about the truth of Veer's betrayal, she feels utter loneliness. At one place also Maya's feeling of loneliness is seen when she says"Until Veer arrived, I had found no-one in town to spend time with" (p. 182). The idea is clearly shown here that Maya wants someone to be with her. Maya's loneliness is also conveyed metaphorically, "In winter the barbet calls all day from its lonely perch high in a leafless tree. Is plaintive, monotonous cry is the distillation of solitude and sadness" (p. 235).

Diwan Sahib, who gives Maya protection by providing her a room, was also a lonely person. He talks about his journey of life throughout the novel and he tries to show himself as a very happy person. Many times in the novel, he has pangs of loneliness while talking. It appears that he has isolated himself as Maya tells about him- "Diwan Sahib had thrust away memories of past grandeur and lived a solitary life as the local eccentric" (p. 197). Diwan wants to break away from his old memories and sometimes wants to live in isolation. Maya says-

Diwan Sahib was fiercely private. I was the only person he ever allowed close: to argue with, confide in, joke with, or scold...and I had left, knowing that he now wanted to be alone. He was not the kind of person who could share his life with anyone else. He had been single all his life and it was plain he disliked constant company (Roy, p. 30).

The insecurity of Maya's father of being left alone is visible when Maya says- "Once when my mother protested, "She will be married, she won't be your daughter anymore, she'll have her own life and she may want other things," my father snapped at her. "She will live here and run the business, and I'll arrange a husband for her who lives with us" (p. 63)? Maya's father doesn't want to leave Maya under any circumstance. Maya describes her father's hidden fear of being left alone- "I can see now that my father sensed even then that he was losing me, and everything he did was an attempt somehow to corral me, to reclaim our lost days of easy happiness when I was willing disciple and he my unquestioned master" (p. 63). By these lines, Maya's father had sensed that Maya was then going to be separated from him.

Maya also explains her mother's loneliness by saying- "For much of her later life, even before I left home, my mother had stopped sharing father's bed. She seldom allowed anyone else into her own bedroom, cleaning it herself and guarding it as an inviolable refuge...." (p. 190). When Maya's father disinherits Maya, then her mother feels as if she was left all alone due to Maya's departure. Further Maya tells about her mother- "the only thing she dreamed of now, she had said in the letter's three dipping lines, was a glimpse of me, and after that, death" (p. 197). Veer, in his own way, is also a victim of loneliness:

....he was sent from the house of one relative to another as a child, parceled out between them on school holidays. How none of them ever had time for him. How he grew attached to one or two of them, and hoped they would announce all of a sudden that they were his parents. How, by magic, he would know where he belonged and would have a real home....How Veer had hungered for

5726 
affection and never found any....How I had yearned to comfort Veer in his loneliness then" ( $\mathrm{p}$. 256)!

Veer, who has been seen as a betrayer in this novel, has had a very bitter and lonely childhood. A sense of loneliness does prevail in the characters of The Folded Earth. The author seems to have brought the theme of loneliness in a subtle manner, but it has some strong undercurrents in the novel.

Psychological Explanations behind Loneliness of the Characters

Osho says "....The way children are brought up is the cause of this whole misery. No child is accepted as he is. He is rewarded if he follows the directions of the parents, the teachers, the elders. Those directions may go against his nature, because those directives were not made by him or for him...." (Loneliness is...., 2020). Reasons for loneliness are innate or psychological; not outer or circumcised. Superficially it appears that Maya's loneliness depends upon the external causes like her estrangement by her parents and in-laws, her loss of her husband, Veer's betrayal, Diwan's lesser concern for her etc. But it is just a tip of iceberg. There is something else in the trough.

According to Erikson there are eight stages through which personality development takes place, from infancy to adulthood. The second stage is 'Autonomy vs. Shame and doubt' which starts at the age of 18 months and ends at around 3 years of age. In this stage a child learns to have control over physical skills and a sense of independence. If children are supported in this stage and if their independence and will is valued and respected, they get a confidence to live on their own. But did it happen with Maya as her father always tried to impose his own yearning upon her? Maya's father says- "Get your head out of the clouds, Maya, life is not lived on a cloud" (p. 63). Maya says- ".. he forced me out of the house and into his car. "You don't become a businesswoman unless you learn to be tough. You have to be steel inside....On the drive, he would lecture me all the way: Business is all about decisions that..." (p. 64). It depicts that Maya was not free in her actions and was in pressure made by her father from her infancy.

From the overall talk of Erikson, the idea comes out that if children are not given space and are overly controlled, they begin to feel inadequate in this ability to survive and they become dependent on others for their sense of being right or wrong. And they lack selfesteem. They can feel guilty and doubts in their actions. And it happened with Maya. Maya says, "I could have chosen differently. I could have found a better-paid job elsewhere. I could have returned to my own family....All I had to do was to tell him that I had been wrong and misguided, and I beg him to trust me again" (p. 20). Maya loved and married someone by her own choice. She was not necessarily wrong but still she was feeling guilty and not confident in her own actions.

Some innate causes of Maya's loneliness can also be supported by Erikson's fifth stage of identity vs. role confusion. This development occurs between 12-18 years when one finds one's identity, personal beliefs, values and goals. A person wants to become independent in actions but unconsciously confused between childhood and adulthood, which go together with the professional and sexual individualities (Saul Mcleod). "According to Bee, what should happen at the end of this stage is, a reintegrated sense of self, of what one wants to do or be, and of one's appropriate sex role" (Quoted in Saul, 1992).

Coercion in this stage can make a person defiant and an undesirable identity may get established within him/her. Maya also becomes rebellious because she could not complete this stage of 'identity vs. role' successfully because of over control of her father. Her father's dominance causes her to marry Michael even more because even after imposing all restrictions, she marries Michael. A kind of stubbornness and resistance develops in Maya's subconscious which results into the sense of loneliness.

Unlike Maya, Veer's loneliness is rather a reclusion in which Veer moves away from people and commitments. Although in worldly sense he did betray. His betrayal is a result of his reclusive tendency. There are significant reasons hidden behind his actions. Veer is a mountaineering guide in the novel with whom Maya falls in love with. Veer also made endearments and promises to her but he always stays away from others especially from Maya. Readers may think that due to Veer's guilt of not saving Michael's life during a mountaineering expedition in which both were together, Veer escapes from Maya. But this is not necessarily true. The bitterness of life makes Veer, a reclusive. What were the conditions with Veer because of which he could not fulfill any

5727 
commitments? This can be understood by some psychological reasons.

The first stage of psychosocial development of Erikson's theory is trust vs. mistrust (birth to 18 months). Herein children have full dependency on their first caregiver. In the presence of good care, love with reliability and consistency, he develops trust and faith in himself but if he is not met with these things, then suspicion, mistrust in others, anxiety and reclusion develops into him. Saul McLeod explains it- "Failing to acquire the virtue of hope will lead to the development of fear. This infant will carry the basic sense of mistrust with them to other relationships. It may result in anxiety, heightened insecurities, and an over feeling of mistrust in the world around them" (2018).

Veer could not qualify successfully in this stage because he did not get care, predictability and reliability by his caregivers. In fact he lacked the sense of belonging and did not know about his true identity and of his parents. Maya tells about him:

How none of them ever had time for him. How he grew attached to one or two of them, and hoped they would announce all of a sudden that they were his parents. How, by magic, he would know where he belonged and would have a real home...how Veer had hungered for affection and never found any (p. 256)!

The above suggests that Veer had a traumatic childhood that is why suspicion, reclusion, escaping commitments, selfishness, mistrust, anxiety and lack of stability develops in Veer. Bitterness of life had made him bad. One more innate reason can be responsible for Veer's behaviors. May be Veer was also reclusive due to these reasons. Lisa Fritscher explains, "Prolonged distress may be a sign of insecure attachment and may, in extreme cases, be an indicator of an anxiety disorder. This fear is common in small children. It is generally considered a normal part of development and is not diagnosed as a condition like separation anxiety disorder unless it lasts later into childhood or is unusually severe" (Jan, 2020).

The novel conveys that Maya suffered a lot due to her father's dominance who disinherits and estranges her mercilessly. Psychologically speaking, nobody is bad. People have reasons behind their actions. Some, who seem to be cruel, themselves suffer the most. Dominance of Maya's father can be understood through of generativity vs. stagnation, stage of middle adulthood. If a person contributes something positive to the society by nurturing things, children or work successfully, one feels useful and accomplished while disqualification leads to a feeling of shallow involvement in the world. McLeod makes it understand well- "By failing to find a way to contribute, we become stagnant and feel unproductive. These individuals may feel disconnected or uninvolved with their community and with society as a whole. Success in this stage will lead to the virtue of care" (2018).

Now it seems like, Maya's father wants to mark himself in the society as a significant person by making Maya a great businesswoman. He pampers her and brings her up in a grand way without feeling of sadness of not having any son. He subconsciously follows a defense mechanism of 'displacement' in which a person fulfils his suppressed desires by other ways, when not possible by one way. Displacement, according to Fluet, is "diversion of emotions such as anger and irritation from an original source to a substitute target" (Quoted in Jerina \& Chithra, 2020, p. 596). Traditionally male child is always wished for as only he can carry on the legacy but because Maya's father does not have any son that's why he decides to hand over his legacy to his daughter proudly to show it to the society that he is not unproductive. He disinherits her daughter on marrying a Christian man, may be because he wants to show it to the society that he also obeys the norms of it.

Erikson says that if we find our life, unproductive then we fall into despair and guilt. We can feel lonely. So Maya's father must have felt lonely because he also found his life, unproductive. Maya says- "...he forced me out of the house and into his car. "You don't become a businesswoman unless you learn to be tough. You have to be steel inside." He would say. On the drive, he would lecture me all the way: Business is all about decisions that..." (p. 64). It shows that Maya was not free in her actions and was in pressure indirectly made by her father from her infancy.

Conclusion

Loneliness is one of the social problems of $21^{\text {st }}$ century. Today most people are not happy despite 
having all the wealth and facilities in their lives. "Modern man is a mass man. $\mathrm{He}$ is highly "socialized," but he is very lonely" (Fromm, 1992). Loneliness may prove very fatal to people. Due to it, people have been victim of many diseases as Grover et. al. tell- "Loneliness is associated with higher severity of depression, anxiety, and somatic symptoms. Severity of depression is associated with loneliness but not with social connectedness" (2018). Ever since communication has become easier, the number of friends of people has increased. It's not a question of isolation. It is a question of loneliness as it is known that loneliness is an internal feeling which has nothing to do with having people around or not. It comes from inside.

Actually a child comes in this world with a sense of loneliness, which prevailed even in the early human times. Therefore it used to live with everyone in congregation. People did not have their personal spaces like today and because of this, they had interdependency for their livelihood and other necessities. Being in groups, they had little chance to be alone or experienced the feeling of loneliness. However today, facilities have increased; people have their own jobs and houses; they are prosperous and this has given food to their ego. Now the expectations to enjoy their happiness without any compromise, have taken hold. Preference to privacy has increased. Now as there is no crowd of people around them, they feel lonely, whereas this aloneness was there from the very initial stage of life. "All those voices of your parents and teachers and priests and the politicians are recorded in the mind; the mind simply goes on repeating them" (Osho. Loneliness is...., 2020).

It seems that human beings are themselves responsible for their behavior and what life gives to them. Circumstances and their associates may superficially appear to be responsible, but in reality what matters is their attitude (psychology) towards life as a whole. In the wake of the increasing problem of loneliness in society, it would not be out of place to discuss in brief ways to come out this problem, as suggested by some scholars. Many superficial solutions are suggested in this regard like- joining somebody's company, joining some club or institute, reviving old relationships, diverting attention by doing something creative or passive etc. But all these solutions are temporary and uncertain. Ezra Bayda writes- "It is said that we are all born alone and that we all die alone, and in between it is our connectedness with others that takes the edge off of our basic aloneness" (2018). First of all Bayda asks to accept that basically man is alone from birth to death. Bayda suggests the three R's "recognize, refrain, and return" (Byda, 2018). By 'recognize', she means that one should understand one's exact feelings. Then comes, 'refrain' which means that one should control the rampant thoughts of oneself. Lastly is, 'return' which means that one should quickly return to and come to terms with the present moment of loneliness.

Osho, the renowned Indian spiritualist, adopts the same direction, by insisting on mind control. "You are not mine. I came into the world without you.You have been given to me later on by education, by example. So at least when I am alone, leave me alone. You have to learn to say, 'Shut up!' to the mind, and allow your nature full freedom" (Loneliness is...., 2020). Further Osho says- "You will be immensely surprised what beauties you have, what innocence, what perceptiveness. Once you have learnt that the mind can be put aside, and you can be really alone..." (Loneliness is...., 2020). All such Osho's suggestions match with Bayda's suggestions. According to Fromm "the only thing that could save humanity from its own soul-destroying loneliness is the individual's ability to inhabit what came to be known as the 'authentic' self. If you achieved authenticity, you would be rewarded with the inner peace necessary to become a free agent who is happy to do unto others as you would have others do unto you" (Quoted in Friedman, 2013). Swan's idea hovers in similar direction, "When you align all the inner twins within you, and they are no longer lonely in their separate realities, then you will no longer be a match to loneliness in your life either" (2018). In a way, a lonely person should enjoy his/her separation from others and should consider himself/herself an authentic entity. If the person is psychologically healthy then he/she will think in the right direction.

Textual evidences show that the characters, especially Maya, Maya's parents, Veer and Diwan Sahib are victims of loneliness or reclusiveness. It is also clear that there is no antagonist in the novel who intrigues against anyone intentionally. Therefore whatever sufferings are there, are the consequences of 
characters' inner conflicts. After studying all the aspects, the result seems to be that, that if a child is psychologically underdeveloped since infancy, it may become the cause of disoriented life. There is no indication in the novel regarding characters coming to terms with their loneliness. Perhaps, Anuradha Roy has deliberately left this part out for readers to make their own headways in this direction according to their own perspectives.

The novel focuses on the issue of loneliness - a problem with which many people are suffering in real life too. Hence readers tend to identify their loneliness with that of the characters. The issue raised in the present research can give an understanding of this problem, its reasons and solutions. It can help people in their catharsis and can prove effective in the skill of dealing with loneliness. Loneliness in life must be taken care of as it can be treacherous and may incite the loner to take drastic steps like suicide.

References

1. Adler, Alfred. (1927). Understanding Human Nature: A KEY TO SELF- KNOWLEDGE. Leipzig:

Fawcett.

2. Bayda, Ezra. (Winter 2018). "At Home with Yourself, Learning to be alone without being lonely". https://tricycle.org/magazine/athome-with-yourself/

3. Callanan, Bill. (1997). "Loneliness as a theme in the life and writings of C.G. Jung". Irish Association of Humanistic and Integrated Psychotherapy. Winter, issue 31.

4. Chang, Edward C. et. al. (2017). "Loneliness and suicidal risk in young adults: does believing in a changeable future help minimiz suicidal risk among the lonely?". The Journal of Psychology, vol. 151, No. 5, Pp- 453-463.

5. Courtin, Emillie \& Knapp, Martin. (2017). "Social isolation, loneliness and health in old age: a scoping review". Health in Old Age, vol. 25. Issue 3, Pp. 199-812.

6. Erikson, Erik H. (1963). Chilhood and Society. London: Vintage.
7. Friedman, Lawrence J. (March 1, 2013). “The lives of Erich Fromm: Love's Prophet”. Boston Review. http://bostonreview.net/booksideas/vivian-gornick-cure-loneliness

8. Fritscher, Lisa. (Jan, 13, 2020). "Monophobia: The Fear of Being Alone”. verywell mind.

9. Fromm, Erich. (1989). The Art of Being. Rainer Funk (Ed.). New York: Open Road Integrated Media.

10. Grover et al. (2018). "Relationship of loneliness and social connectedness with depression in elderly: A multicentric study under the aegis of Indian Association for Geriatric Mental Health". Journal of Geriatric Mental Health, vol. 5, issue 2, Pp. 99-106.

11. Hawkley, Louise. (2007). "Encyclopedia of social psychology". Britannica.

https://www.britannica.com/science/loneliness

13. Jerina, Jove \& Chithra, G.K. (2020). "Getting through the cognisant minds of the characters in Anuradha Roy's Sleeping on Jupiter". Journal of Critical Reviews, vol. 7, issue 5, Pp. 595-596.

14. Jung, C.G. (1989). Memories, Dreams, Reflections. Aniela Jaffe (Ed.). Clara Richard Winston (Tr.). $U S$ : Vintage.

15. Kemph, John. (Mar, 1969). "Erik H. Erikson. Identity, youth and crisis. New York: W. W. Norton Company, 1968". Behavioral Science, vol. 14, Pp. 154-159.

16. Mcleod, Saul. (2018). "Erik Erikson's Stages of Psychosocial Development". Simply psychology. https://www.simplypsychology.org/ErikErikson.html 
17. Oppong, Thomas. (Nov 21, 2019). "The

Psychology of Loneliness And What You Can Do

About It."

\section{Medium.}

18. Osho. (2020). "Loneliness is pain, aloneness is peace; hmm?". Osho International Foundation. https://www.osho.com/read/featuredarticles/other-myself/loneliness-is-pain-aloneness-is-peace-

19. Perlman, Daniel \& Peplau, Letitia Anne. (Jan, 1981). Toward a Social Psychology of Loneliness. London: Academic Press.

20. Rakwal, Komal. (2020). "Deep Ecological Philosophy in Anuradha Roy's the Folded Earth". International Journal of Advanced Science and Technology, vol. 29, No. 3, pp. 4162-4173.

21. Roy, Anuradha. (2011). The Folded Earth. Gurgaon: Hachette Book.

22. Roy, Anuradha. (2018, Jul 16). "Inequality in India has never been more catastrophic". Interview. The Gaurdian.

23. Roy, Anuradha. (September 12, 2020). "We are great competition for the tortoise in matters of change': Anuradha Roy". Interview. The Hindu.

24. Swan, Teal. (2018). The Anatomy of Loneliness: How to Find Your Way Back to Connection. UK: Watkins.

25. Tanskanen, Jussi \& Anttila, Timo. (2016). “A Prospective Study of Social Isolation, Loneliness, and Mortality in Finland". American Journal of Public Health, 106 (11), Pp. 2042-2048.

26. Winch, Guy. (Oct 1, 2015). "How to beat loneliness". TED Ideas- TED Talks. https://ideas.ted.com/how-to-beat-loneliness/ 